\title{
Pensando sobre el riesgo alimentario y su aceptabilidad: el caso de los alimentos transgénicos ${ }^{1}$
}

\author{
Thoughts on eating risk and its acceptability: \\ the case of transgenic food
}

Mabel GRACIA ARNAIZ²

RE S U M E N

En la última década se han llevado a cabo numerosos trabajos con el objetivo de analizar la percepción social de la seguridad alimentaria y, en particular, las representaciones sociales del riesgo. La mayoría de estos estudios tratan de dar respuesta a por qué ha ido aumentando la percepción negativa que la población tiene sobre determinadas aplicaciones tecnológicas en los alimentos y, en general, sobre la alimentación industrial justo en el momento en que la comida es muy abundante, la cadena alimentaria está más controlada que nunca, la esperanza de vida de las personas ha alcanzado los niveles más altos o los problemas de salud relacionados con la alimentación, aún persistiendo, tienen unas dimensiones menos dramáticas que en épocas anteriores. Se insiste, sin embargo, en la idea de que hoy sabemos menos o poco acerca de lo que comemos. Si bien es cierto que una parte de esta valoración negativa se puede atribuir a los cambios habidos en las nuevas formas de vida y a la separación que se ha producido entre las actividades de la población y la producción o preparación de sus alimentos, otra parte se debe a la sucesión de las diferentes alertas y crisis alimentarias que a lo largo de este periodo se han producido en el contexto europeo y de las importantes consecuencias que han tenido en términos políticos, económicos y sociales. En este sentido, el debate público surgido en torno a los organismos modificados genéticamente y, en particular, los alimentos transgénicos constituyen un caso paradigmático para ilustrar desde una perspectiva antropológica la variabilidad cultural respecto a su aceptación o rechazo.

Palabras claves: alimentos modificados genéticamente, seguridad alimentaria, alimentos, representaciones sociales.

\footnotetext{
1 Este artículo sintetiza algunas de las cuestiones tratadas en los proyectos de investigación "La percepción social de la seguridad alimentaria: relaciones entre información mediática y representaciones sociales del riesgo alimentario" financiado por el Ministerio de Educación, Cultura y Deportes de España y "El impacto de la biotecnología: la percepción social de las aplicaciones alimentarias" financiado por el Ministerio de Ciencia y Tecnología (Programa Nacional de Biotecnología 2000), coordinado por el Grupo de Estudios Alimentarios de la Universidade de Barcelona.

2 Universitat Rovira I Virgili, Departamento de Antropología, Filosofía y Trabajo Social. Plaza Imperial Tarraco, 1. Tarragona, España.E-mail: maga@fll.urv.es
} 


\section{A B S T R A C T}

In the last decade, numerous studies have analysed society's perception of eating safety and, in particular, the social representations of risk. Most of these studies attempt to explain why the negative perception that people have of certain technological applications in food and, in general, of industrial food has increased just when food is abundant, the food chain is under greater control than ever before, life expectancy is at an all time high and food-related health problems, although they still exist, have less dramatic consequences than in previous ages. It is stressed, however, that today we know less or little about what we eat. Although it is true that this negative assessment is partly due to the changes in the new ways of life and the fact that the activities of the population have become separated from food production or preparation, it is also partly due to the succession of food-related incidents and crises that have taken place in the European context and the important political, economic and social consequences that they have had. In this respect, the public debate that has arisen around genetically modified organisms and, particularly, transgenic food is a paradigmatic case that illustrates the cultural diversity in relation to their acceptability or repulse from the anthropological perspective.

Index terms: food, genetically modified, food safety, food, social representation.

\section{INTRODUCCIÓ N}

El artículo que se presenta a continuación pretende mostrar, en primer lugar, las principales teorías elaboradas desde las ciencias sociales, y especialmente desde la antropología y la sociología, que han abordado el carácter complejo de los procesos que intervienen en la construcción social del riesgo alimentario. Seguidamente, se presentan los resultados de diferentes estudios que, centrándose en el análisis de la percepción social de los alimentos transgénicos, han constatado la diversidad de actitudes culturales respecto al rechazo y/o aceptación de este tipo de productos, así como las razones que las motivan.

En el actual contexto internacional, las cuestiones relativas a la seguridad alimentaria ocupan un lugar prioritario en las agendas científicas, políticas, económicas o sanitarias. De ahí que se hayan convertido en un tema de interés también para las ciencias sociales, especialmente por su relevancia y alcance social. Se trata, no obstante, de un término ambiguo, al menos semánticamente hablando. Seguridad alimentaria ha querido decir siempre, y en nuestra opinión tendría que seguir así, que una población dispone de recursos alimentarios suficientes para garantizar su supervivencia, su reproducción y su bienestar. Esta acepción hace referencia al término inglés food security siendo claves los conceptos de disponibilidad y accesibilidad. Como bien sabemos todos esta circunstancia no es real todavía para una gran parte de la gente que vive en este planeta. En numerosos países de África, América del Sur y Asia existen serias dificultades para alimentar a una buena parte de sus poblaciones: el hambre, las hambrunas y la malnutrición por carencia de alimentos afectan a más de ochocientos millones de personas ${ }^{1}$. Sin olvidar tampoco que este problema, estrechamente ligado con la desigualdad social y el reparto desequilibrado de los recursos, también afecta a numerosas personas de los denominados "países ricos". En este mismo informe, la FAO presenta también estimaciones totales del número de personas que sufren subnutrición en los países industrializados y en transición. La cifra resultante, que alcanza los 44 millones de personas (10 y 34 millones respectivamente), confirma que incluso estos países tienen que enfrentarse al reto de superar la inseguridad alimentaria. Aunque la inmensa mayoría de esos 38 millones de personas vive en sociedades que han experimentado importantes transformaciones políticas y económicas en la década de los años noventa, 
existen focos de hambre repartidos por todo el mundo. Sin ir más lejos, se calcula que más de 800 mil familias estadounidenses padecen hambre. En el caso de España, la extensión de la pobreza, entendida por aquellas personas y familias que se sitúan económicamente por debajo del umbral del cincuenta por ciento de la renta media neta disponible en el conjunto del estado, alcanza a 2.192.000 hogares en los que viven 8.509.000 personas, estando en situación de "pobreza extrema" un total de 86.800 hogares y 528.200 personas cuyo nivel de renta les impide acceder de forma regular a los alimentos y les hace depender de los recursos sociales públicos y/o privados para poder comer, conforme estudios sobre pobreza y condiciones de vida de Caritas 2002.

Existe, todavía, un uso más reciente para el término de seguridad alimentaria. Aquel que se refiere al consumo de alimentos libres de riesgos para la salud. Todas las sociedades toman precauciones para minimizar los posibles peligros asociados a los alimentos, como la intoxicación o la contaminación, mediante la manipulación específica, las técnicas de conservación o, aún, la evitación. En inglés, tal idea se expresa mediante el concepto de food safety. Sin embargo, para algunos estudiosos, utilizar el término "seguridad alimentaria" o el de "inseguridad alimentaria" en este segundo sentido es, consecuentemente, no sólo impreciso y confuso, sino incluso absurdo e indecente. Por esta razón, hay quienes prefieren emplear el término de seguridad sanitaria de los alimentos o de la cadena alimentaria2-4.

En los últimos diez años en Europa se han llevado a cabo una cantidad considerable de trabajos con el objetivo de analizar la percepción social de la seguridad alimentaria siguiendo esta segunda acepción y, en particular, las representaciones sociales asociadas al riesgo alimentario ${ }^{5-8}$. La mayoría de estos estudios tratan de explicar por qué ha aumentado la percepción negativa que la población tiene de la alimentación industrial y de determinadas aplicaciones tecnológicas - es el caso de los alimentos transgénicos. Esto ocurre justo en el momento en que la comida es muy abundante, la cadena alimentaria está más controlada que nunca, la esperanza de vida de las personas ha alcanzado los niveles más altos o los problemas de salud relacionados actualmente con la alimentación, si bien existen, presentan, sin embargo, unas dimensiones menos dramáticas que los de épocas anteriores.

En efecto, una buena parte de las observaciones que se pueden recoger sobre el sistema alimentario contemporáneo apuntan en la misma dirección: nunca en la historia del mundo occidental una población había tenido tanto qué comer ni había estado tan libre de las hambrunas o de la escasez como hasta ahora. Nunca hubo, en ese sentido, tanta seguridad alimentaria. Sin embargo, seguimos inseguros, con numerosas incertidumbres/dudas acerca de lo que come y si esta comida puede entrañar riesgos, es decir, daños potenciales/probables para su salud. Según el CREDOC ${ }^{9}$, si en 1997 el 35\% de los franceses opinaban que los productos alimentarios presentaban algunos riesgos para la salud y el $20 \%$ decían que presentaban riesgos importantes, tres años después, en el 2000, estas valoraciones se habían hecho más negativas, aumentando al $40 \%$ y el 30\% respectivamente. En una línea semejante, el $\mathrm{CIS}^{10}$ mostraba que el $46,7 \%$ de españoles tenía poca confianza en que los alimentos que compraba fueran sanos y no implicasen riesgos para su salud y el 15\% no tenía ninguna confianza. Es decir, la mayoria de la población, aumentaron las dudas acera de la inocuidad alimentaria.

\section{Construyendo el riesgo o de la emergencia de una nueva sociedad}

\section{El riesgo y las sociedades modernas}

Para abordar las dimensiones y significados de las incertidumbres generadas en relación con el consumo alimentario se ha recurrido a los enfoques teóricos elaborados en torno al concepto 
de riesgo en las dos últimas décadas desde las ciencias sociales ${ }^{(3)}$, especialmente desde la sociología y la antropología, y que sintetizamos aquí mediante dos aproximaciones distintas: por un lado, la sociedad del riesgo de Beck ${ }^{11,12}$, Giddens $^{13,14}$ y Bauman ${ }^{15,16}$ y, por otro, la teoría cultural de Douglas y Wildasky ${ }^{17}$, Douglas ${ }^{18,19}$, Bellaby $^{20}$, Boltanski y Thévenot ${ }^{21}$.

Los teóricos que han adoptado el enfoque de la sociedad de riesgo generalmente han tendido a centrarse en los aspectos macroestructurales de la organización económica y política de las sociedades modernas tardías y sus implicaciones en las conductas de las personas en su vida cotidiana; ellos sitúan la causa principal de la creciente intensificación de la ansiedad en torno a la salud o el medio ambiente en cuestiones más generales sobre los efectos negativos de la modernización e industrialización. La preocupación por el riesgo, desde esta perspectiva, es una respuesta racional a las percepciones individuales de las nuevas incertidumbres y peligros. La sociedad moderna no sólo se singulariza por su capacidad de producir riqueza, sino también de crear/fabricar riesgos (manufactured risks) a través de su sistema productivo y científico; riesgos que, al margen de toda lógica probabilística y matemática son difíciles de calcular y prever.

En relación con el consumo de alimentos, en las denominadas sociedades del riesgo, do que podria haberse visto previamente como ventajas de la industrialización ahora están siendo sopesadas por los peligros que conllevan la producción y procesamiento de alimentos a escala masiva ${ }^{22,23}$. Desde esta perspectiva, los riesgos relacionados con los alimentos son del mismo orden que otras ansiedades contemporáneas: respuestas lógicas a las consecuencias de la organización de la producción y de aplicaciones tecnológicas que han supuesto la degradación medioambiental por pesticidas, fertilizantes o manipulación genética, entre otros. Los alimentos procesados muestran, por su parte, como productos peligrosos para la salud por la falta de fibra y vitaminas, su alto contenido en grasas, azúcar y sal o por sus componentes químicos, tales como los aditivos. De forma paralela, la industria alimentaria se presenta como un agro-business en donde lo que importa es el beneficio, aunque sea en detrimento de la calidad de lo que se produce o del bienestar de los animales, mientras que los gobiernos son vistos como los alcahuetes de ese negocio, faltos de convicción para introducir regulaciones estrictas que aseguren la seguridad en la producción de alimentos.

En estas sociedades modernas, los expertos (especialistas, técnicos) tratan de identificar las causas y el alcance de los riesgos, así como proponer soluciones para su gestión, pero a menudo sin unanimidad entre ellos. La actividad científica ahora parece desprovista de razones frente a los efectos de algunas aplicaciones tecnológicas, o lo que es peor, es percibida como una de las fuentes de riesgo. Así es como aparece la controversia y el debate, y también la reflexividad: en las sociedades modernas la gente piensa sobre los riesgos, reflexiona hasta que punto son evitables o hasta que punto puede/ quiere aprehenderlos, es decir, vivir con ellos.

Los individuos, por su parte, manejan los riesgo al nivel colectivo o individual mediante respuestas lógicas. Ante la posibilidad de que ciertos alimentos puedan estar contaminados, las

\footnotetext{
${ }^{3}$ Dependiendo del enfoque disciplinar, el riesgo ha sido usado en diferentes sentidos: hay quienes lo distinguen de peligro (exposición física a una amenaza), otros se refieren a una amenaza probable (pero puede que no entrañe ningún daño), otros incluyen un matiz relacionado con el azar (juego...). En cualquier caso, el sentido que se da aquí es el de daño potencial referido, en principio, a una realidad posible, aunque no necesariamente objetiva. Por otro lado, en su obra Social Theories of Risk, Krimsky y Holding (1992: 67-79) clasifican y explican diferentes aproximaciones hechas sobre el riesgo desde la sociología y la antropología entre los años setenta y finales de los ochenta. Dichas aproximaciones se mueven en torno al concepto de actor racional, la teoría de la movilización social, la teoría organizacional, la teoría de sistemas, la teoría crítica y neo-marxista, el construccionismo social y la teoría cultural (Conceptual and historical perspectives, social theories of risk, London, Praeger, 1992).
} 
personas modifican los productos consumidos y/o su preparación y también introducen cambios en su clasificación entre alimentos "buenos" y "malos" para comer. A su vez, ante el cuestionamiento de las instituciones públicas y científicas, la población renegocia sus identidades sociales y morales y ello puede tener como resultado nuevas redes, movimientos y organizaciones más o menos informales, tales como organizaciones no gubernamentales, asociaciones ecologistas y de consumidores o asambleas de ciudadanos.

Esta primera aproximación de Giddens y Beck se centra, sobre todo, en las respuestas sociales o individuales que se adoptan cuando se conceptualiza y maneja el riesgo derivado de la industrialización, subrayando la paralela ecologización de una buena parte de los discursos políticos en el contexto de los nuevos riesgos para el medio ambiente causados por la innovación tecnológica y los usos reivindicativos del riesgo que se han hecho desde diferentes ámbitos sociales y laborales ${ }^{24}$. Sin embargo, esta teoría se centra menos en cómo la gente construye y representa unos u otros "riesgos" dependiendo del modelo cultural.

\section{Representaciones sociales del riesgo: el prisma de las culturas}

La teoría cultura/ de Douglas y Wildavsky ${ }^{17}$ y sus posteriores reformulaciones ${ }^{20,21}$ parecen dar más luz sobre estas cuestiones, poniendo un mayor énfasis en cómo y por qué determinados fenómenos son susceptibles de problematizarse frente a otros que no lo son. Todos los conceptos socio-antropológicos que se han dado sobre el riesgo en las dos últimas décadas comparten una misma y principal idea: el riesgo es una construcción social. De tal forma que lo que unas sociedades consideran objeto de temor e incertidumbre, para no otras no lo es. Ello significa que los seres humanos no perciben el mundo a través de ojos pristinos, sino a través de lentes perceptuales filtradas por significados culturales y sociales.
Sirvámonos de un ejemplo referido por Hubert ${ }^{4}$ para ilustrar esta idea: cuando hay poco o nada que comer, la valoración del la seguridad y el riesgo es muy relativa. Entre quienes pasan hambre, la certeza sobre si lo que comen es potencialmente dañino posiblemente sea la última de sus preocupaciones. Coincidiendo con la crisis provocada por la Encefalopatia Espongiforme Bovina (EEB), los campesinos sin tierra del sur del Brasil y de otros lugares del mundo sugirieron a las autoridades europeas enviarles los "bovinos locos" que aquí se estaban sacrificando a millares porque existía el riesgo -más o menos remoto- de contraer la nueva variante de la enfermedad de Creuzfeldt-Jacob. En este caso, este colectivo no parecía temeroso ante los potenciales efectos que podía causar dicha dolencia en su salud: una enfermedad que de manifestarse podía hacerlo al cabo de veinte años era algo que a ellos, con una esperanza de vida inferior a la de los europeos, no les quitaba el sueño. Paralelamente, en los países afectados de lleno por la crisis, el riesgo del prión no pareció existir para las personas que confiaron plenamente en las autoridades sanitarias, en los productores y en los distribuidores de la carne bovina y no modificaron sus pautas habituales de consumo de ternera. Por tanto, desde esta perspectiva teórica se mantiene la idea de que a cada unos sus riesgos. Siguiendo a Peretti-Watel ${ }^{8}$, los dos aspectos más importantes de la teoría cultural pueden sintetizarse así:

a) Por un lado, aprehendemos el riesgo dependiendo de nuestro sistema de valores y creencias y de nuestra posición social y personal en el seno de una sociedad dada. Estos valores -variables en el tiempo, limitados- están organizados en sistemas complejos adquiridos por la socialización o la aculturación, y son los que determinan si finalmente un comportamiento o un objeto es preferible o no respecto a otro, de tal forma que cada cultura dispone de "riesgos buenos", que conviene correr, y de "riesgos malos", que se debe evitar. 
Respecto a la dicotomía riesgos buenos y malos, es oportuno insistir en otra cuestión. Con frecuencia, las valores asociados a determinados riesgos representan juicios morales implícitos, aunque enmascarados por el discurso de lo objetivo y de los datos cuantitativos: fumar, beber, tener relaciones sexuales o conducir pueden ser conductas arriesgadas dependiendo de nuestro propio comportamiento ("bueno" o "malo"). Es así como parte de la responsabilidad y de la culpa de un posible daño se traslada al terreno individual. Ello se aprecia constantemente en los discursos médicos y de salud pública que exhortan a las personas a conformar "dietas" que eviten enfermedades/riesgos para la salud, a auto-controlarse, es decir, a ser responsables consigo mismas.

Además, las ideas sobre seguridad/ inseguridad alimentaria no son representadas de igual modo por los miembros de un mismo grupo social, pudiendo variar en función del género, la edad, la clase o la profesión. Tampoco todas las ideas tienen que ver sólo con la salud y la enfermedad. Hay personas para quienes el riesgo de engordar no consiste en contraer una obesidad mórbida, sino en dejar de tener un cuerpo socialmente aceptable: el peligro, en este caso, sería dejar de estar delgado.

b) En consecuencia con lo anterior, se concluye la aceptabilidad del riesgo no depende del nivel de competencia técnica que tenga la población, puesto que existen diferentes puntos de vista para identificar y valorar lo que es, o no, objeto de riesgo.

El clásico estudio de Slovic ${ }^{25}$ señala las diferencias en la percepción social del riesgo para treinta actividades tecnológicas (energía nuclear, rayos $X$, pesticidas...) según cuatro grupos diferentes de individuos (asociación de mujeres, club deportistas, estudiantes y expertos). Para la mayor parte de actividades, el riesgo percibido es distinto entre los especialistas y el resto de grupos y también entre estos últimos. El caso de la energía nuclear, por ejemplo, es muy ilustrativo. Siguiendo un orden decreciente de riesgo, para el grupo de mujeres dicha actividad se sitúa en el primer puesto del ranking, para los miembros del club deportivo en el octavo, mientras que para los expertos se sitúa en el número veinte.

A propósito de dicha variabilidad, Douglas critica la frecuente aceptación de la dicotomía que se presenta entre riesgos objetivos y subjetivos: los primeros (los saberes expertos) son basados en una probabilidad matemática y evaluados por los especialistas; los segundos (los saberes profanos) son basados en la percepción social/ psicológica de la población y de mayor debilidad cognitiva. Partiendo de las diferentes valoraciones que unos y otros hacen sobre la misma actividad, los expertos suelen deplorar la irracionalidad de la población que percibe "mal" los riesgos: el hombre de la calle se inquieta por una nuclear, mira su bistec de través, prueba el maíz modificado con una mueca, lo que no le impide encender un cigarro bebiendo un vaso de vino o coger el volante incluso ebrio. Desde su perspectiva, la probabilidad de morir en carretera o de cirrosis es mucho más alta que de la contraer la nueva variante de la enfermedad de CreuzfeldtJacob $^{26}$.

\section{Saberes expertos, saberes profanos}

Aparece así la disyuntiva entre los saberes expertos y los saberes profanos. Los primeros evalúan y miden el riesgo; los segundos, acaso lo perciben o representan. Aunque sólo los expertos (técnicos, científicos, especialistas) disponen de los instrumentos que permiten cuantificar los riesgos y, en consecuencia, fijar su existencia -la estadística, el cálculo de probabilidades, etc.-, ni siquiera ellos están provistos siempre de razones objetivas para dar cuenta de todos los daños potenciales. Podemos preguntarnos por qué. La respuesta tiene que ver con el hecho de que no todos los riesgos se conocen tan bien como los accidentes de carretera, por ejemplo. Por otro lado, resulta que ante un mismo fenómeno las evaluaciones sobre el riesgo pueden ser dispares 
e incluso contradictorias, incorporando con ello la controversia entre los propios expertos ${ }^{27}$.

Ciertos affaires alimentarios, como es el caso de la crisis de las vacas locas o del debate surgido en torno a la inocuidad de los alimentos transgénicos, han puesto de manifiesto lo difícil que es evaluar el riesgo según una lógica probabilística, en razón de la existencia de dudas o desconocimiento científico, sea sobre la Encefalopatía Espongiforme Bovina y sus mecanismos de transmisión, o sobre las consecuencias medioambientales de liberar organismos modificados geneticamente (OGM) en campos abiertos $^{28}$. Insistiendo en que el riesgo cero no existe, los expertos han optado por aplicar el principio de precaución ${ }^{29}$ en cierta ocasiones: un principio de acción que, ante peligros potenciales graves o muy graves y dentro de un contexto de incertidumbre científica, incita a prevenir el peligro sin esperar a tener prueba de dicha incertidumbre.

Ahora bien, si se acepta que existen diferentes formas de aprehender el riesgo, incluso de definirlo, parece más propio no apelar a la falta de lógica racional de los profanos o, lo que es lo mismo, de la población en general, tal como suelen reclamar los expertos. Las valoraciones de los profanos, aunque distintas, son legítimas ${ }^{(4)}$. En lugar de ello, habría que preguntarse a qué obedecen y cual es la naturaleza de su preocupación ${ }^{30}$. Es una simplificacón presentar a la población como siendo incapaz de comprender los argumentos científicos y manipulada por los media. A menudo, las valoraciones profanas son fruto de conocimientos empíricos e incluso previsibles: los riesgos nuevos son menos aceptados que los riesgos conocidos (familiaridad), los riesgos naturales suscitan menos indignación que los ligados a la actividad humana (causalidad), se tolera mejor un riesgo que ha sido escogido deliberadamente (elección) y mal, aquel que parece transgredir el orden natural de las cosas (manipulación).

Por otro lado, no sólo la percepción los riesgos no es uniforme en el seno de una población dada, sino que refleja de forma muy ilustrativa las desigualdades sociales frente a los mismos riesgos $^{8}$. Estas desigualdades se concretan de diferentes modos. En el terreno laboral, por ejemplo, de cada diez víctimas por accidente de trabajo con resultado de incapacidad permanente, siete son obreros, frente a un empleado y un directivo. En el ámbito urbanístico, las zonas residenciales donde se concentran las personas de renta más baja son aquellas con un nivel de ruidos, olores, polución y degradación de los equipamientos más alta, mientras que los delitos por robos, agresiones, intimidaciones, etcétera, son el doble que en el resto del territorio.

Así pues, son las experiencias y las ideas que las personas se van generando sobre una técnica o aplicación, las que construyen sus percepciones $\mathrm{o}$, mejor dicho, las representaciones sociales del riesgo ${ }^{(5)}$, entendidas como aquellos conceptos relativos a objetos cuyo sentido es construido y compartido de forma colectiva ${ }^{31-33}$. Hoy, la mayoría de la población acepta positivamente la congelación de los alimentos, mientras que, hace treinta años atrás, no sucedía lo mismo. Sin embargo, parece poco o nada dispuesta a consumir alimentos que, sin reportarle

\footnotetext{
4 Según Chateauraynaud y Torny ${ }^{8}$. Éstos explican, a través de tres dossiers sobre el amianto, las vacas locas y las fuentes de radioactividad, cómo los "profanos vigilantes" pueden convertirse en los "lanzadores de la alerta", sustituyendo a expertos deficientes, incapaces o pocos deseosos de alertar a la opinión pública y adquiriendo por ellos mismos experiencia y una competencia técnica y científica. El caso del mal de las vacas locas es muy significativo: profanos y expertos pueden defender dos concepciones distintas del conocimiento y de la acción.

5 La diversidad de las percepciones del riesgo tropieza con el sentido habitual del término percepción, por lo que estos estudiosos prefieren utilizar el concepto de representación. Percibir es probar una sensación, tocar una realidad tangible. No obstante, los riesgos que aludimos no son necesariamente percibidos, son a menudo imperceptibles: el prión de la vaca loca como el gen transmutado escapan completamente a nuestros cinco sentidos. Por esta razón, se considera más oportuno recurrir al término de represen-taciones sociales, entendidas como conceptos relativos cuyo sentido se genera a partir de la conveniencia social.
} 
beneficios aparentes (materiales o simbólicos), puedan suponer un peligro innecesario para su salud.

\section{La construcción social de las incertidumbres alimentarias}

\section{La inseguridad alimentaria: ¿miedo a qué y por qué?}

Resuelto el primer nivel de la subsistencia humana, la población de las sociedades industrializas centra ahora su interés en saber si su alimentación, elegida más o menos libremente y entre numerosas opciones, es fiable en términos de calidad e inocuidad. Las innovaciones en materia de producción, procesamiento, conservación y distribución (mayor disponibilidad, más higiene, más cantidad de comida, precio más barato...) han incluido tantos aspectos positivos que, en las expectativas de la población, cuesta encajar la posibilidad de que ello ocurra a expensas de la calidad y la seguridad de los alimentos.

Sin embargo, persiste la idea de que hoy sabemos menos o poco acerca de lo que comemos. Si bien es cierto que una parte de esta valoración negativa se puede atribuir a los cambios habidos en las nuevas formas de vida y a la separación que se ha producido entre las actividades de la población y la producción o preparación de sus alimentos, otra parte se debe a la sucesión de las diferentes crisis alimentarias que a lo largo de este periodo se han producido en el contexto europeo y de las importantes consecuencias que han tenido en términos políticos, económicos y sociales.

Aunque para los expertos se ha tratado normalmente de "casos" aislados y/o irrelevantes (retirada parcial del aceite de orujo o de pollos con dioxinas, sacrificio de vacas con EEB, cese de las importaciones de aves asiáticas, etcétera) puesto que el número de personas afectadas y la probabilidad de contraer alguna enfermedad grave o, incluso de morir, ha sido inexistente o muy baja, para la población dichos problemas han alcanzado otra significación. El conocimiento y el alcance social de los diferentes "casos", alguno no tan irrelevante desde el punto de vista de la salud como fue el derivado del consumo de aceite de colza desnaturalizado, han contribuido al cuestionamiento de la cadena alimentaria. Una cadena que, aún estando científica y legislativamente más controlada que nunca, presenta de forma más o menos regular algunos "fallos", a la vez que pone en evidencia aplicaciones tecnológicas cuya existencia y naturaleza se desconocía previamente: por ejemplo, suministrar al ganado vacuno harinas cárnicas elaboradas a base de ovejas enfermas con el objetivo de aumentar la producción de leche o abaratar los costes de producción.

La población es sensible a todo este tipo experiencias recurrentes, las cuales conforman, a su vez, las representaciones sociales. Este reconocimiento fortuito e inesperado del riesgo en algo tan cotidiano y necesario como es la comida, y especialmente en los alimentos básicos y mejor valorados (carnes, cereales, pescados), se ha venido traduciendo de distintas maneras por la población. Ésta expresa una mayor desconfianza hacia la cadena alimentaria y muestra un escepticismo generalizado frente a la manera de gestionar y resolver políticamente los problemas que le atañen directamente, ya sea en términos de salud, o de economía o de medio ambiente.

En materia de alimentación, la población no parece querer aceptar riesgos innecesarios y considera poco útiles o ventajosas algunas de las aplicaciones de las innovaciones científicas y tecnológicas en el ámbito de la comida. Como es el caso de alargar la maduración de frutas y hortalizas para que puedan estar más tiempo en cámaras frigoríficas o en los lineales de los establecimientos alimentarios, por ejemplo.

La incertidumbre social ha implicado en ciertas ocasiones un cuestionamiento del modelo 
científico o de ciertos objetivos de la ciencia, pero sobre todo un escepticismo generalizado frente al modelo de gestión política. Cada controversia alimentaria pone de manifiesto las mismas cuestiones - incertidumbre, ocultación de información, medidas insuficientes, evaluaciones científicas contradictorias - y la población tampoco detecta cambios sustantivos en las maneras de actuar y dar respuesta a los nuevos problemas que van surgiendo ni en el modo de informarles o tener en cuenta sus opiniones.

Por su parte, los organismos modificados genéticamente (OGM) y, en particular, los alimentos transgénicos (AGM), constituyen un caso paradigmático para analizar la construcción de las representaciones sociales en torno a los riesgos alimentarios. En apenas una década, se ha pasado de una situación en la que los AGM se consideraban artículos cualesquiera sin restricción en su producción y comercialización, avalados, además, por numerosos argumentos positivos como la posibilidad de acabar con el hambre mundial, reducir costes de producción o hacer superalimentos, a otra situación en la que se ha tenido que aplicar el principio de precaución y moratorias de facto tras la postura política adopotada por numerosos países europeos de someter a controles más rigurosos cualquier producto GM antes de su comercialización y evitar así posibles riesgos para la salud o el medio ambiente ${ }^{(6)}$.

\section{Algunos datos sobre los alimentos modificados genéticamente (AMG)}

En primer lugar, hay que señalar que los OGM y, en concreto, los alimentos modificados genéticamente, son el resultado de aplicaciones biotecnológicas. La biotecnología, por su parte, tiene como objeto el estudio científico de los métodos y aplicaciones cuyo soporte son los seres u organismos vivos para la obtención y mejora de productos, tales como alimentos o medicamentos. Los OGM son organismos cuyo material genético (ADN) ha sido intervenido y alterado artificialmente redefiniéndose sus características (ingeniería genética). En un sentido amplio, el alimento transgénico es aquel cuya materia prima ha sido modificada genéticamente, también aquel alimento en el que el microorganismo causante de la fermentación ha sido modificado genéticamente o aquellos alimentos que Ilevan una sustancia o aditivo alimentario obtenido por ingeniera genética (almidones, enzimas, lecitinas, etcétera) $)^{35}$.

En el ámbito alimentario, dichas aplicaciones afectan principalmente a los vegetales, animales y fermentados, aunque el campo de las aplicaciones agrícolas es el que ha experimentado un mayor crecimiento. De acuerdo con los datos elaborados por el Servicio Internacional sobre la Incorporación de la Biotecnología en la Agricultura (ISAA), la superficie cultivada con vegetales transgénicos ha pasado de apenas 200.000 hectáreas cultivadas en 1995 a más de 57 millones en todo el mundo en 2003. La superficie cultivada destinada a su comercialización se reparte, no obstante, entre trece países, acaparando el 99\% de la producción sólo cuatro de ellos: Estados Unidos, Argentina, Canadá y China. El $1 \%$ restante se reparte entre Australia, Sudáfrica, Rumania, Bulgaria, Ucrania y México. En la Unión Europea, los principales productores son España, Portugal y Francia. Entre dichos cultivos, destacan la soja, el maíz, la colza, los tomates o la chicoria. En estos momentos, hay más de trescientos alimentos que permanecen a la espera, ya en fase final, sea de experimentación o de aprobación para su comercialización ${ }^{36}$.

\footnotetext{
${ }^{6}$ En la primavera de 1999, la Comisión Europea formulaba el esquema de un Plan de Emergencia de cinco puntos para hacer frente a accidentes graves con organismos transgénicos incluyendo planes para descontaminar y aislar las áreas afectadas y para destruir las plantas y animales expuestos a OGM semejante al formulado para ser aplicado en caso de un accidente nuclear ${ }^{34}$.
} 
En un principio, todo el mundo se tenía que beneficiar de los OGM: productores, agricultores, ganaderos, piscicultores, distribuidores, consumidores. Unos, vendiendo semillas y productos agroquímicos; otros, sacando mayores rendimientos a sus campos, animales o peces; otros, pudiendo almacenar durante más tiempo los productos; finalmente, los consumidores, comiendo alimentos con mejor sabor, más nutritivos o más baratos. Se les suponían tantos beneficios que, en un primer momento, llegó a plantearse, incluso, que los AGM podrían acabar con el hambre planetario $y$, en consecuencia, garantizar la seguridad alimentaria mundial. Sin embargo, la mayor parte de las aplicaciones biotecnológicas han tenido como objetivo responder a los intereses económicos o biomédicos originados en los países denominados del "primer mundo": producir plantas libres de enfermedades, plagas y resistentes a herbicidas; acortar tiempos de maduración en quesos o conseguir vinos con un incremento del aroma afrutado; construir animales transgénicos que portan múltiples copias del gen de la hormona de crecimiento de otras especies para ganar tamaño mucho más rápido; modificar genes para retardar la madurez sexual y aumentar su tamaño; crear animales transgénicos para una mejor eficiencia alimenticia; descubrir y mejorar nuevas vacunas y diagnóstico de enfermedades; desactivar proteínas causantes de intolerancias entre otras posibilidades.

En definitiva, salvo algunas excepciones, como es el caso de los cultivos que se están realizando en Nicaragua y Costa Rica o en otros países tropicales con la yuca y la batata aumentando su contenido en aminoácidos o incluyendo hierro o sustancias precursoras de la vitamina $A^{34,37,38}$, la finalidad de las aplicaciones biotecnológicas agroalimentarias han estado orientadas exclusivamente para beneficiar a ciertos sectores de la industria agropecuaria alimentaria y a grupos muy específicos de la población de las sociedades industrializadas aunque, como señalan Ramón y Calvo ${ }^{35}$, no sería difícil construir variedades de papaya capaces de crecer en suelos ácidos, diseñar alimentos que actúen de vacunas e incluso se puedan conseguir variedades de arroz transgénico con un alto contenido de provitamina A y hierro capaces de solucionar los problemas de avitaminosis en las sociedades en desarrollo donde este cereal es la base de la dieta.

\section{La construcción social del riesgo en torno a los AGM}

La cuestión que ahora nos interesa abordar es cuándo y por qué los AGM se convierten en objeto de debate público. A lo largo de la década de los noventa, la sucesión de diferentes fenómenos cuestiona la inocuidad de los alimentos que llegan al mercado y evidencia la falta de controles en la cadena alimentaria. El 20 de marzo de 1996 va a quedarse muy probablemente como la fecha que marca la entrada de las sociedades industrializadas en lo que se ha denominado la era del riesgo alimentario o, en su segunda acepción, de la seguridad alimentaria ${ }^{39}$. Es el día, en efecto, en que el ministro británico de la salud, Stephen Dorrell, anuncia en la Cámara de los comunes la fuerte probabilidad del vínculo entre la nueva forma de la enfermedad de Creuzfeldt-Jakob contraída por algunos individuos y la exposición al agente patógeno de la encefalopatía espongiforme bovina (EEB), mejor conocida bajo el nombre de la enfermedad de las "vacas locas".

A partir de aquel momento y hasta ahora, las noticias televisadas, la radio o la prensa diaria han ido informando regularmente de que el contenido de las comidas cotidianas es susceptible de incluir sustancias potencialmente perjudiciales para la salud humana aunque sea a escala infinitamente pequeña. En lo sucesivo, las imágenes mediáticas conforman una alimentación industrial afectada periódicamente por salmonella, virus, dioxinas, priones u otras sustancias nocivas. En este contexto, se han ido sucediendo con cierta recurrencia situaciones de "crisis alimentarias", es decir, de periodos en los que ante la generación de una alarma la desconfianza de la población se ha manifestado de forma más contundente e intensa, cuestionándose incluso la eficacia de los 
controles y de las medidas políticas. Dichos episodios críticos han coincidido, curiosamente, con el conjunto de medidas adoptadas por la Unión Europea para hacer frente a algunos de los efectos ambientales y sociales que estaba teniendo el sistema de producción agrícola intensivo. Así, ciertos cambios recientemente planteados en la reforma de la política agraria comunitaria pretenden, entre otros, disminuir el uso de pesticidas, potenciar la ganadería intensiva y el cultivo de especies locales de calidad y aumentar las normas y controles sanitarios a lo largo de toda la cadena alimentaria.

Durante la misma década, los ciudadanos europeos conocen otras noticias relacionadas con el sistema agropecuario que tienen como protagonistas los organismos genéticamente modificados y, de forma especial, los alimentos transgénicos. Junto al uso de las harinas cárnicas contaminadas destinadas a la alimentación animal, los AGM son presentados a través de las acciones y tomas de posición de diferentes asociaciones ecologistas (Greenpeace, Los Amigos de la Tierra, Ecoropa, etc.) o de otros agentes y grupos de presión (políticos, sindicalistas, agricultores, científicos, asociaciones de consumidores) como síntomas evidentes de los nuevos riesgos derivados de una agricultura industrial que privilegia la cantidad y el beneficio en detrimento de la calidad, de la preservación de la salud pública y del entorno ${ }^{26,40}$, señalando de forma más recurrente los riesgos que se especifican en el Cuadro 1.

Evidentemente, aquí no vamos a discutir el alcance biomédico, ambiental o tecnológico de estos riesgos. Como antropólogos, carecemos de competencias en este sentido. Pero sí, podemos tratar de dar cuenta sobre por qué los AGM se han convertido en objeto de debate social y han sido rechazados abiertamente o aceptados con reservas por una buena parte de la población europea.

Previas a estas fechas, las comisiones de ingeniería biomolecular de algunos países europeos habían elaborado informes con opiniones favorables a la comercialización del maíz transgénico (de la firma Ciba-Geigy, después convertida en Novartis), considerándose que los riesgos de transferencia de los genes resistentes a los microorganismos presentes en el suelo eran extremadamente débiles. En 1995, se empieza a hablar, no obstante, de las consecuencias del cambio climático y, en algunos países -entre ellos Dinamarca y Austria-, las asociaciones de consumidores protestan, el gobierno prohíbe el cultivo del transgénicos y los agricultores culpabilizan a los laboratorios de hacer experimentación no controlada.

Cuadro 1. Posibles riesgos associados a los OGM.

\begin{tabular}{ll}
\hline Sanitarios & Reacciones alérgicas imprevisibles \\
& Transferencia de la resistencia a antibióticos \\
& Otras reacciones similares a las de animales de laboratorio \\
/... & \\
Dispersión OGM en poblaciones silvestres \\
Susceptibilidad de insectos beneficiosos (no plaga) \\
Reducción de espectro vegetal y animal \\
Mayor uso de sustancias químicas en agricultura \\
/... \\
Control del mercado de semillas modificadas genéticamente por pocas compañías químicas \\
Incremento de desigualdades norte-sur: campesinos pobres dependientes de precios de semillas GM \\
y agroquímicos y de volver al mercado (genes "terminator") \\
Mercantilización de las nuevas formas de vida (patentes) \\
Bio-piratería: apropiación por parte de las empresas transnacionales y de los gobiernos de los países \\
industrializados de recursos genéticos en beneficio propio y en detrimento de los productores autóctonos \\
/...
\end{tabular}


Aunque en la primavera de 1996, en los albores de la crisis alimentaria de las "vacas locas", los AGM no son tenidos en cuenta lo cierto es que el sentimiento de inquietud empieza a crecer y las plantas transgénicas comienzan a ponerse en el punto de mira de ciertos grupos de presión y de una sociedad sensible por las consecuencias planetarias de un problema potencialmente "sólo" localizado en Gran Bretaña. Desde diferentes ámbitos, van surgiendo voces discordantes que cuestionan abiertamente su utilización, a pesar de la inocuidad sostenida por los EE.UU. cuya posición, por otro lado, es claramente favorable al cultivo y comercialización de los OGM. En diferentes países de Europa, empiezan de forma simultánea las movilizaciones entre las asociaciones de consumidores y los grupos ecologistas. Las primeras exigen, entre otras consideraciones, la trazabilidad(7) de las sustancias transgénicas que entran en la composición de los productos alimentarios, recomendando el etiquetaje de todos los artículos que las contengan, mientras que las segundas, impiden el desembarco de las cargas de soja transgénica de la firma Monsanto en los principales puertos de los países europeos y estimulan el movimiento a favor de "tierras sin OGM" apoyados, a su vez, por sindicatos agrícolas.

Algunos investigadores reclaman a los laboratorios el establecimiento de un mayor control de la ingeniería genética, utilizando como argumentos de base las incertidumbres que rodean los efectos de la diseminación de los OGM sobre los ecosistemas y la salud humana o las implicaciones económicas y ecológicas para los países en desarrollo, invocando a la aplicación del principio de precaución. Ante la inminente comercialización de los primeros alimentos transgénicos suizos y norteamericanos, un número creciente de científicos europeos va a recomendar la activación de una moratoria sobre las nuevas diseminaciones. Los poderes públicos entran en escena con el objetivo de regular la controversia a través de los comités de prevención y de precaución formados por expertos. Dichos comités deberán establecer las líneas de actuación sobre la autorización del cultivo y comercialización de las sustancias transgénicas, aquellas que se confirmaran como inocuas, tendrían libres su cultivo y comercialización, y recomendar las demoras oportunas en el caso de aquellas otras sustancias que entrañen riesgos potenciales hasta tener pruebas más concluyentes sobre su inocuidad.

La controversia sobre estos posibles riesgos hace tomar parte en el debate, más allá de los poderes públicos de los gobiernos de cada país, también a la Unión Europea como institución. Desde 1990 esta entidad, ha creado distintos textos para generar un dispositivo de control de los OGM concernientes a su utilización y diseminación. Dichos textos, más que un dispositivo de control, han buscado dotar a la Unión Europea de un marco reglamentario capaz de armonizar las diferentes aproximaciones nacionales en materia de evaluación de la seguridad de los OGM, con el fin de garantizar la libre circulación de los productos dentro del espacio comunitario $^{40}$. Las directivas emitidas desde entonces han generado cientos de informes técnicos, sin tampoco haberse salvado de la controversia. Hoy día, en el panorama europeo las actuaciones gubernamentales, aun intentando evitar el enfrentamiento, han sido variables a partir de las distintas interpretaciones que se han hecho del concepto de "efecto adverso" en relación con el posible daño medioambiental y de la salud; interpretaciones cuyas discrepancias no han hecho más que crecer con el tiempo, ocasionando moratorias para la regulación del cultivo de los OGM en suelo europeo.

La directiva europea sobre vegetales transgénicos aprobada en 2001 y traspuesta recientemente en España a principios del 2003, ha de interpretarse como el paso para el

\footnotetext{
${ }^{7}$ La trazabilidad hace referencia a la posibilidad de rastrear el camino seguido por los alimentos a lo largo de toda la cadeia y se ha convertido en objeto prioritario de la Unión Europea en su invés por responder "a los deseos y exigencias de la sociedad europea" (Libro de Seguridad Alimentaria).
} 
levantamiento de la "moratoria de hecho" impuesta por el parlamento europeo en 1999, puesto que en ella se representan las reglas sobre las que se establecen los mecanismos de control y se define el marco en el que pueden moverse las empresas productoras de semillas transgénicas. Entonces se especuló con que eso sucedería a finales de ese mismo año o, en el supuesto menos optimista, para la primavera del 2002. Al final, y después de numerosas presiones internacionales, a partir del último trimestre de 2003 ha empezada a entrar en vigor en su totalidad, tan pronto se hubieran publicado las normas específicas sobre etiquetado y trazabilidad y sobre responsabilidad ambiental no contempladas en dicha normativa.

\section{Evolución de la aceptabilidad o el rechazo de los AGM: una aproximación transcultural}

La investigación sobre la inocuidad sanitaria y medioambiental de los alimentos transgénicos financiada- a menudo por la inversión privada de laboratorios multinacionales- así como los resultados contradictorios de una parte de estos estudios han servido de base para la controversia pública, dando paso a movilizaciones sociales contra la producción y comercialización de tales alimentos. La sensación de incertidumbre se ha ampliado, a su vez, por la ausencia de sistemas reglamentarios internacionales específicos y por la urgencia con la que numerosos estados de la Unión Europea y de otros lugares del mundo han firmando distintos Protocolos de Bioseguridad (Cartagena, Montreal...) para dotarse de medidas legislativas donde recoger los principios básicos que sirvan para analizar los posibles riesgos de estos productos en la salud humana y el medio ambiente.

Este proceso normativo no ha estado libre tampoco de indecisiones y polémica. Por ejemplo, el 21 de mayo de 1999 la Comisión Europea suspende todos los procedimientos de autorización de los OGM. Sobre esta base, el Consejo de ministros de la Unión Europea anuncia el 25 de junio de 1999 una moratoria para el cultivo de los
OGM en el conjunto de Europa, en contradicción con la reglamentación comunitaria en vigor. Ello, sin embargo, no impide al Parlamento europeo adoptar el 14 de febrero de 2001 una versión revisada de la directiva de abril de 1900 sobre la diseminación de los OGM, reforzando la modalidades de su comercialización, aunque dejando en suspense la cuestión del levantamiento de la moratoria ${ }^{41}$.

Aunque ciertas actitudes frente a las crisis alimentarias han sido parecidas entre las poblaciones donde se han producido, respecto a los AGM las reacciones sociales han sido de distinto tipo e intensidad según los países ${ }^{5,42-44}$. España parte de una posición peculiar respecto al debate en torno a los alimentos transgénicos. Las diferentes encuestas europeas y estatales ${ }^{45-50}$ que se han ido realizado en los últimos años muestran que la opinión de los españoles se ha ido modificando de forma significativa. Habiéndose mostrado inicialmente menos indispuestos que otros países a las aplicaciones biotecnológicas con la finalidad de mejorar, sea el gusto o la calidad de ciertos alimentos o su resistencia a los insectos (la tasa de aceptación en el año 1997 era del $53 \%$, frente a países como Austria o Dinamarca, que sólo mostraban el $18 \%$ y el $30 \%$ respectivamente), en los estudios más recientes los españoles se muestran más reacios a su aceptación y sólo el 35\% de la población estaría de acuerdo en aplicar estas técnicas para mejorar supuestamente algunas cualidades de los alimentos. A pesar de ello, en el contexto europeo nuestro país, junto a Portugal, Finlandia e Irlanda, sigue mostrando una mayor aceptación respecto a la media de países, especialmente en lo relativo al uso de semillas transgénicas. Esta evolución invita a la reflexión.

Analizar las actitudes del público respecto a las biotecnologías y, en particular, a los organismos modificados genéticamente, constituye una área de investigación desarrollada desde hace una década, promovida especialmente, aunque no sólo, por los propios políticos y gestores de la actividad científica y tecnológica, a quienes les interesa saber cómo representa la población la actividad científica y técnica. En 
general, la aceptación pública de la ciencia es positiva, aunque se discrepa en cuestiones concretas: respecto a las biotecnologías, por ejemplo, se aceptan mucho mejor las aplicaciones médicas que no las alimentarias ${ }^{51}$. Así para los, europeos consultados en el último barómetro ${ }^{52}$ sobre seis aplicaciones específicas biotecnológicas, ciertos desarrollos biomédicos tan controvertidos como la puesta a punto de tests genéticos para comprobar la existencia de enfermedades hereditarias o la clonación de células y tejidos humanos con fines terapéuticos se consideran moralmente aceptables a pesar de los riesgos éticos que comportan, y convienen que se apoye cierto tipo de investigaciones. Sin embargo, las valoraciones son muy distintas cuando se pregunta acerca de los alimentos transgénicos. En general, se consideran que no son alimentos útiles y que generan un riesgo excesivo para la sociedad. Aun dándose una opinión ligeramente más favorable hacia las semillas transgénicas, el balance en el conjunto europeo sigue siendo, según este gráfico, negativo (Figura 1).
Aunque la lectura de los sondeos y encuestas puede ser muy ambivalente, el análisis comparado entre periodos aporta datos interesantes sobre las tendencias en la aceptación o rechazo de los alimentos transgénicos, así como sobre ciertas especificidades culturales. Para ilustrar dicha tendencia, Cheveigné et al. ${ }^{44}$ han comparado los resultados extraídos de los eurobarómetros de 1996 y 1999 entre, por un lado, la pregunta que suscitó mayor rechazo y la que, por otro lado, registró mayor tolerancia: mejorar el gusto y mejorar la resistencia respectivamente. Los países están ordenados según el porcentaje creciente de aceptación a partir de la encuesta de 1996. Los primeros resultados expresan una notable variabilidad cultural.

Las interpretaciones hechas sobre estas diferencias han sido variadas, refiriéndose a la idiosincrasia cultural, el grado de industrialización o la ignorancia científica. La propuesta explicativa de Cheveigné, Boy y Galloux es interesante. Dichos autores, son partidarios de argumentar las

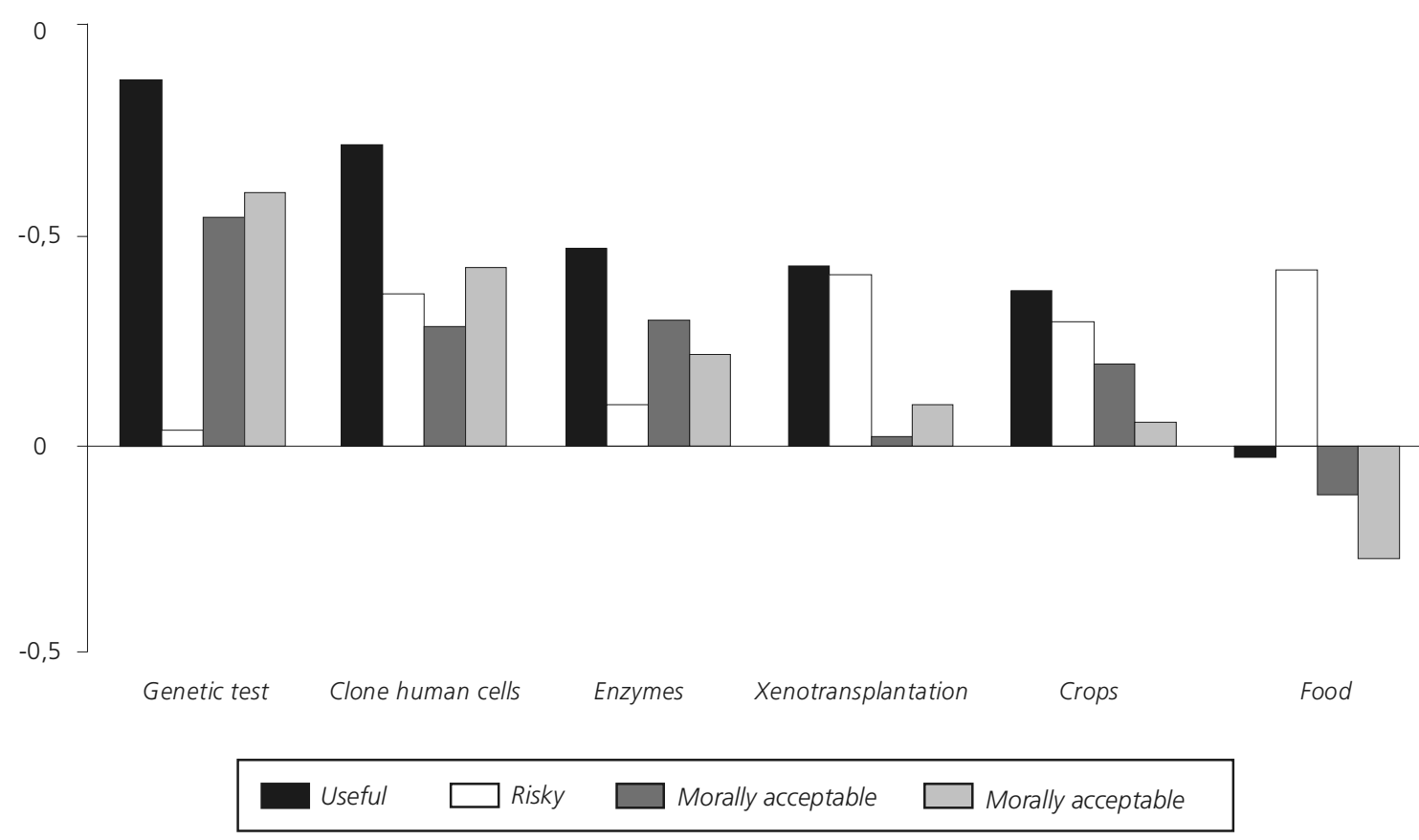

Figura 1. Actitudes de la población europea a seis aplicaciones de biotecnología 2002. Fuente: Eurobarómetro 58.0. Gaskell et al. ${ }^{52}$. 
diferentes actitudes, considerando tanto la dinámica de las políticas tecnológicas, como la intensidad de los debates que éstas han podido suscitar. Observando los datos de estos gráficos, podemos ver dos grandes grupos de países (Figuras 2 y 3 ).

A) Aceptación superior a la media europea. Incluye países del sur, tales como España, Portugal, Italia y Grecia y también Finlandia, Bélgica y Holanda. En el caso de los cuatro primeros, las actitudes favorables se han explicado por la mejor aceptación de la novedad científica y tecnológica, debida a una situación de menor industrialización y ausencia de debate público, mientras que el caso de Holanda se ha justificado por todo lo contrario, es decir, por su mayor "madurez" institucional.

En una posición más o menos intermedia y oscilante aparecen Gran Bretaña y Francia.

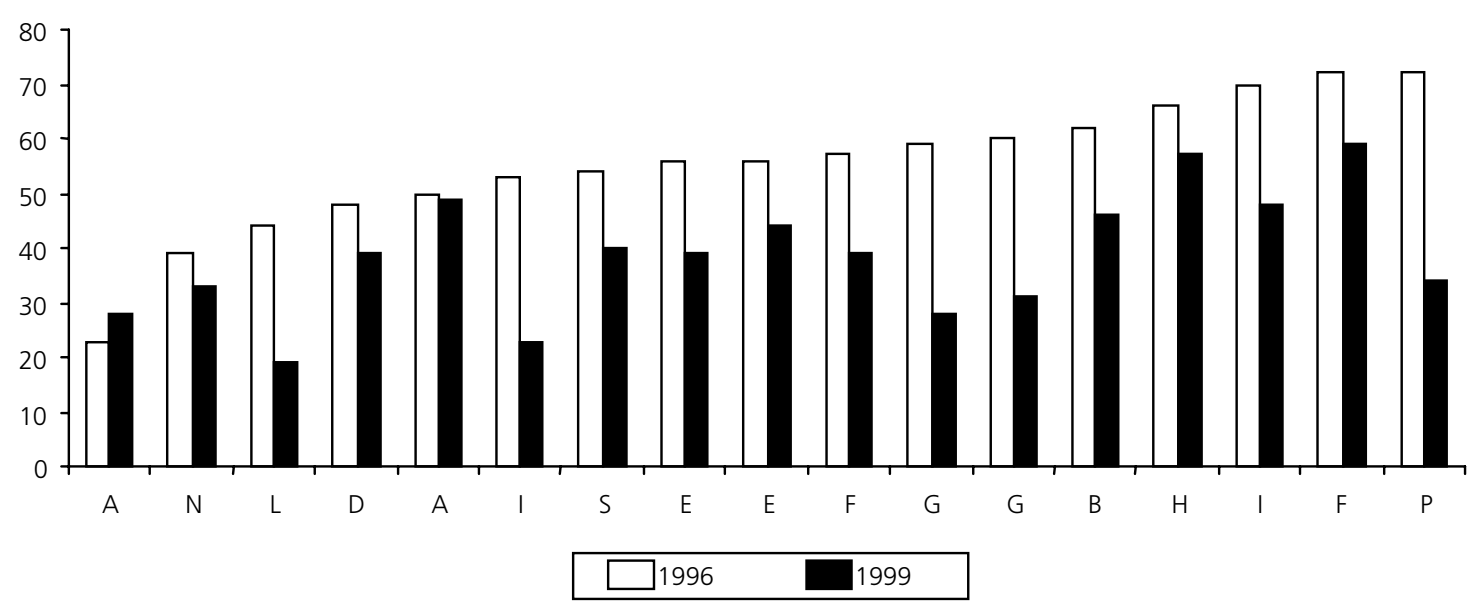

Figura 2. Mejorar la resistencia de ciertas plantas.

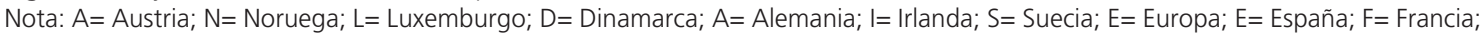
$\mathrm{G}=$ Gran Bretaña; $\mathrm{G}=$ Grecia; $\mathrm{B}=$ Bélgica; $\mathrm{H}=$ Holanda; I= Italia; F= Finlandia; $\mathrm{P}=$ Portugal.

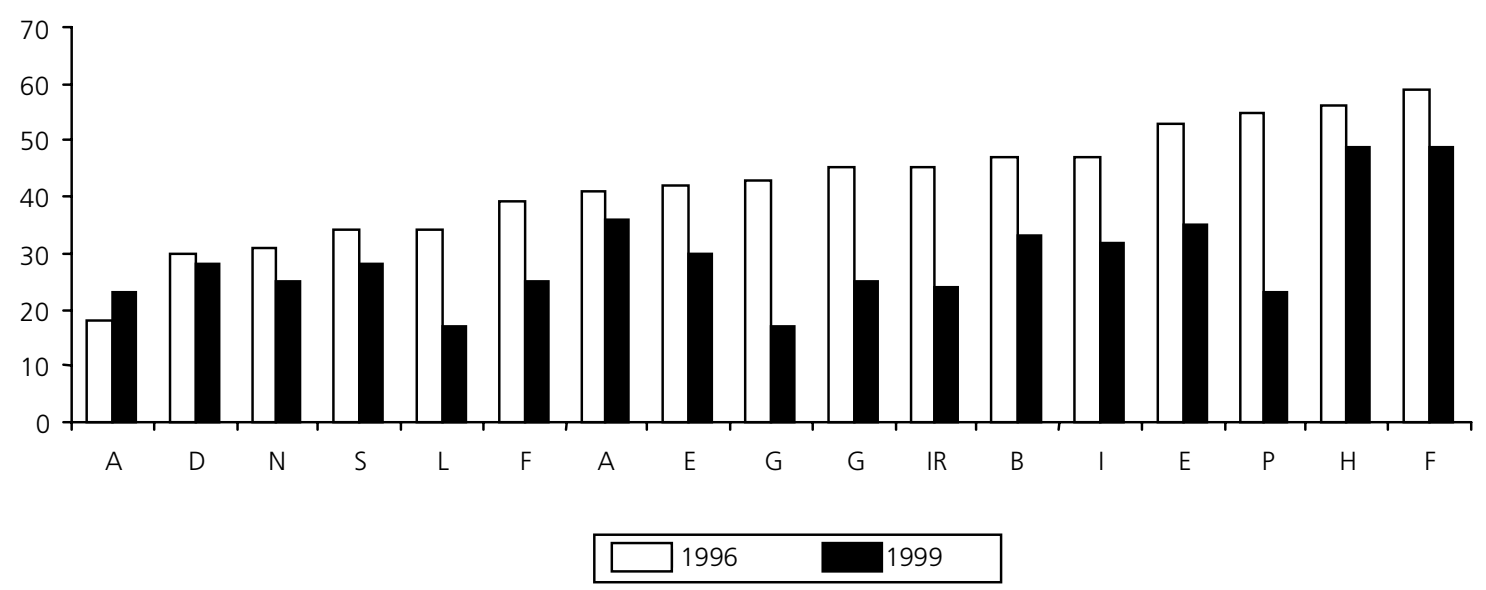

Figura 3. Mejorar el gusto.

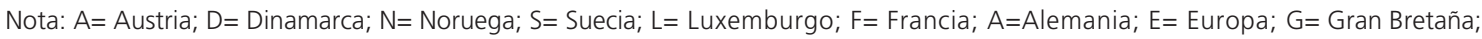
$\mathrm{I}=$ Irlanda; $\mathrm{B}=$ Bélgica; $\mathrm{I}=\mathrm{Italia} ; \mathrm{E}=$ España; $\mathrm{P}=$ Portugal; $\mathrm{H}=$ Holanda; $\mathrm{F}=$ Finlandia. 
B) Rechazo superior a la media europea. Los países nórdicos (Noruega, Dinamarca, Suecia) y del este europeo (Austria y Alemania) se muestran más reticentes ante los avances técnicos y más inquietos ante sus consecuencias perversas, sobre todo en relación al medio ambiente y a la salud. En cualquier caso, se trata de sociedades donde el debate sobre las biotecnologías se ha desarrollado muy pronto y donde existe una tradición crítica del desarrollo científico y técnico. Esto se traduce en un activismo medioambiental elevado, una predisposición a las asambleas nacionales a las discusiones sobre estas cuestiones y una movilización importante de la opinión pública y, lo que es también muy relevante: un marco legislativo precoz y prudente.

Sin embargo, la presencia o ausencia de un debate público precoz no lo explica todo o, en cualquier caso, puede explicar tendencias opuestas: ciertos países donde el debate había sido precoz, han seguido manteniendo una actitud más positiva (Holanda, con reglamentaciones que han adelantado incluso a la legislación europea y con numerosos debates públicos), mientras otros, negativa (Austria). Respecto a la evolución de la aceptación, estos dos eurobarómetros muestran que es negativa para todos los países, excepto para Austria. De nuevo se puede observar en el conjunto de Europa dos grupos diferenciados: el grupo donde el retroceso ha sido más pronunciado -casi más de 20 puntos de media- incluyen a España, Portugal, Grecia e Irlanda, mientras que el grupo que a priori se había posicionado de forma hostil, presenta una evolución más modesta -es el caso, de Suecia, Noruega, Dinamarca o Austria-. En este sentido, aun habiendo posicionamientos dispares, se señala una tendencia a la homogenización frente al rechazo de estas aplicaciones.

Como señalábamos más arriba, los resultados del último eurobarómetro ${ }^{52}$ presentan España como uno de los países que muestra de forma más clara la aceptación del uso de semillas genéticamente modificadas e incluso de alimentos transgénicos. Sin embargo, dichos porcentajes globales no reflejan bien, o en cualquier caso, no matizan lo suficiente, las valoraciones de la población española sobre los AGM. Para España, estudios realizados por el CIS en 1997 ya mostraban que la mitad de los españoles (48\%) no estaban dispuestos a consumir alimentos transgénicos, lo cual concuerda mejor con la actitud reacia hacia las aplicaciones biotecnológicas manifestada con posterioridad y que, según los datos de las últimas encuestas realizadas por el $\mathrm{CIS}^{45,46}$, confirman un grado de rechazo considerable, cuestionando así los hipotéticos beneficios y su necesidad. Los españoles prefieren alimentos no transgénicos frente a los modificados genéticamente, pero se muestran dispuestos a aceptarlos en el caso de que se demuestre científicamente que aportan un beneficio claro para la salud, que implican una disminución de la aplicación de pesticidas o insumos químicos y que no son perjudiciales para el medio ambiente, ni tampoco para la biodiversidad agrícola. Es decir, la mayor aceptación estará en función de demostrar, por un lado, su utilidad y, por otro, los peligros potenciales.

\section{Las representaciones sociales ante los alimentos transgénicos}

Estudios realizados desde una perspectiva socioantropológica aportan matices culativo diferentes sobre el porqué de la aceptabilidad o el rechazo de estos productos entre la población europea y, en particular, la española. Recurrimos a tres investigaciones principales. La primera hace referencia al trabajo realizado en cinco países por el grupo PABE ${ }^{53}$ (Public Perception of Agricultural Biotechnologies in Europe)(8), cuyos resultados dan cuenta de los factores complejos que conforman la diversidad de los puntos de vista acerca de las aplicaciones biotecnológicas agrícolas, tanto de los ciudadanos como de los principales agentes

\footnotetext{
${ }^{8}$ Estudio financiado por la Comisión of European Communities, FAIR-CT98-3844 (DG-12-SSMI) y realizado en España, Gran Bretaña, Francia, Italia y Alemania (http://www.inra.fr/ sed/science-gouvernance); diciembre 2001.
} 
implicados en la controversia. En una línea semejante el segundo trabajo, coordinado por el grupo Grupo de Estudios Alimentarios de la Universidad de Barcelona ("El impacto de la biotecnolgía en España: la percepción de las aplicaciones alimentarias"(9), estudia qué tipo aplicaciones generan un mayor rechazo o aceptación y las causas de la diversidad de actitudes ante los alimentos transgénicos. Por otro lado, analiza los canales por los que se difunde la información sobre las biotecnologías y los efectos que ésta tiene en la percepción social. Finalmente, el tercer trabajo "Representaciones mediáticas del riesgo alimentario: el caso de los alimentos transgénicos"(10), estrechamente vinculado con los objetivos del anterior proyecto, aborda el tipo de relaciones que se producen entre las representaciones mediáticas del riesgo alimentario y las representaciones sociales de la población, dando cuenta de si ambos tipos de representaciones circulan necesariamente a la vez y en el mismo sentido.

Los tres estudios tienen en común la utilización de técnicas cualitativas para la recogida de la información. Es el caso de los grupos focales, la observación participante, las entrevistas en profundidad y semi-dirigidas y, cuando ha sido preciso, el análisis de contenido para los soportes mediáticos. Tales estudios han optado por este tipo técnicas deliberadamente, justificando las ventajas o limitaciones de cada una de ellas ${ }^{(11)}$. En los dos últimos trabajos, la aproximación etnográfica se muestra como una vía eficaz para analizar las representaciones sociales alimentarias, dado que prioriza la combinación de todos aquellos instrumentos analíticos que favorecen la observación, la descripción y el análisis de los conocimientos y habilidades de los miembros de una población dada. Las representaciones sociales alimentarias aglutinan aspectos variados, unas veces relacionados con valores morales o materiales, la desigualdad social, el grado de satisfacción individual o social, el sentimiento de identidad colectiva o, en fin, la adaptación y la supervivencia. Estos múltiples aspectos, participando de la esfera tanto íntima como pública de las personas, son a menudo transformados por la oralidad y por los discursos que construyen los informantes ${ }^{54}$, de tal manera que se hace necesario recoger la información mediante recursos analíticos que permitan la contrastación: de ahí que sea vital combinar técnicas que favorezcan la recogida de información mediante la observación directa o participante de las prácticas alimentarias y las entrevistas abiertas o focalizadas.

Mientras que los grupos focales, utilizados primeramente en el ámbito de los estudios de mercado y luego incorporados como técnica de análisis sociológico, favorecen el intercambio de opiniones o debates y la formulación de preguntas entre los diversos participantes, a la vez que muestran el grado de variedad de los puntos de vista que existen sobre un mismo tema ${ }^{55-57}$ las entrevistas en profundidad, aplicadas individualmente, permiten conocer de forma extensa las valoraciones personales que los informantes hacen sobre un tema específico, teniendo en cuenta que, al recurrir a preguntas abiertas o focalizadas, se recogen los matices significativos que la mayoría de cuestionarios cerrados desestiman. Por su parte, la observación directa se ha incorporado para abordar el decalage que puede existir entre la visión que las personas proporcionan de sus representación alimentarias, en este caso sobre los alimentos transgénicos, y lo que realmente

\footnotetext{
9 Proyecto de investigación financiado por el Programa Nacional de Biotecnología, BIO2000-0947(2000-2003), cuya memoria de resultados acaba de ser redactada por el equipo investigador, siendo éstos todavía inéditos.

10 Investigación financiada por el Ministerio de Educación y Ciencia (España) mediante una becapostdoctoral en Centre d'Etudes Transdiciplinaires de Sociologie, Anthropologie et Histoire (École des Hautes Etudes en Sciences Socials et Centre Nacional de la Recherche Cientifique, París).

11 Para el primer trabajo, la justificación metodológica se especifica exhaustivamente en las primeras treinta y seis páginas del documento citado y puede consultarse en http://www.inra.fr/sed/science-gouvernance, mientras que en el segundo y tercer estudio los recursos técnicos se justifican en las primeras veinte páginas de las respectivas memorias de investigación, aunque de momento se trata de trabajos inéditos.
} 
hacen (si evitan su consumo o no y por qué): una diferencia no siempre fácil de reconocer y valorar cuando el contacto que se produce entre interlocutor y observador se reduce a escasos minutos de diálogo. Por otro lado, numerosos cuestionarios cerrados que no se han hecho sobre la base de una aproximación cualitativa previa incluyen un riesgo metodológico importante consistente en establecer generalizaciones a partir de las respuestas a cuestiones que sólo responden al discurso generado por el diseño de las mismas preguntas. Este tipo de encuestas suele ser insuficiente, sobre todo si éstas no se contrastan ni se construyen teniendo en cuenta la dimensión cualitativa. Las variaciones entre el comportamiento alimentario real, la visión que dan y que construyen los entrevistados, están llenas de significación acerca de la lógica alimentaria y se escapan fácilmente a los valores "medios" resultantes de los análisis exclusivamente cuantitativos.

Los resultados de estas investigaciones muestran dos cuestiones principales respecto a la aceptabilidad o el rechazo de los AGM. La primera cuestión se refiere a las actitudes de la población hacia las aplicaciones de las biotecnologías, actitudes que no dependen sólo de que tales aplicaciones se asocien a riesgos potenciales. Aquellos estudios muestran que el balance entre utilidad y riesgo no es simétrico, como a menudo se imagina. Una aplicación considerada inútil o innecesaria es rechazada antes mismo de se evaluar su riesgo. Mejorar el gusto y/o la durabilidad es considerado "inútil y arriesgado" por más de la mitad de los europeos, mientras los españoles consideran como no muy acertado que los alimentos transgénicos sean beneficiosos y poco arriesgados. Podemos preguntarnos si el rechazo al desarrollar de alimentos transgénicos está motivado por la aprehensión de un riesgo potencial, o mejor porque no se percibe en ello una utilidad clara. Un contra-ejemplo lo constituye el teléfono móvil. Ante la utilidad percibida de este nuevo medio de comunicación, las dudas sobre los riesgos eventuales de las ondas electromagnéticas no han desanimado a la población a seguir usándolo.

En el caso de los alimentos transgénicos, los consumidores no perciben ninguna utilidad para sí mismos. Los alimentos transgénicos introducidos en el mercado no han tenido ningún beneficio directo para la mayoría de personas. No son más económicos, no han distanciado su fecha de caducidad, no tienen mejor sabor. No es extraño entonces que se instale un cierto sentimiento de escepticismo e incredulidad hacia dichos productos y sus potenciales atributos. Los comentarios extraídos de entrevistas de grupos de discusión son, en este sentido, muy significativos:

- "Aumentar el contenido en proteínas puede ser útil. Cambiar el gusto, lo dudo a no ser que sea a peor. A la vista está".

- "Que las frutas y verduras duren más quizá tenga beneficios para quienes las llevan y traen o las venden, pero no para nosotros. Duran lo justo o ni eso. Se pudren al cabo de dos días de haberlas comprado. Son todas iguales, muy bonitas pero carísimas y encima, lo peor de todo es que no saben a nada".

- " ¿Por qué se gasta tiempo y dinero en hacer este tipo de alimentos?. Tienen menos gusto, están menos buenos. La comida es más cara cada vez. Alguien habrá que salga ganando, ¿el comercio, las industrias?...".

Por otro lado, el tipo de cuestiones que los informantes expresan en sus relatos evidencian que las ideas que articulan sus representaciones sociales del riesgo alimentario no son tan irracionales como plantean los expertos, sino que atienden a incertidumbres lógicas:

- ¿Qué necesidad tenemos de alimentos transgénicos? ¿Cuáles son los beneficios inmediatos?

- ¿Quién ha decidido desarrollarlos y por qué se ha tomado esta decisión?

- ¿Por qué no hemos estado mejor informados de su utilización en nuestra alimentación diaria antes de que llegaran al mercado? 
- ¿Podemos decidir si queremos o no consumir estos productos?

- ¿Las leyes que se van aprobando a qué intereses responden: de la población, de las empresas, de los agricultores...?

En este contexto, el término "útil" tiene un sentido no precisamente referido al beneficio altruista, sino al beneficio empresarial o comercial. Estos estudios cualitativos muestran, además, que aunque la población tenga limitados conocimientos sobre la transgénesis y la evolución de la investigación biotecnológica o sobre la reglamentación y la comercialización de estos productos, esta falta de conocimientos no es la que explica sus reacciones negativas o su baja aceptación de las biotecnologías agroalimentarias. Aunque eso es lo que creen los agentes implicados, especialmente los políticos y expertos, el proceso no es tan sencillo. En general, las inquietudes expresadas por los participantes no están fundadas en creencias erróneas sobre los alimentos transgénicos. Se trata de valoraciones basadas en otro tipo de conocimientos, tal como señala el resumen del informe del grupo $P A B E^{53}$.

- Conocimientos no especializados sobre el comportamiento de los insectos, plantas y animales (las abejas vuelan de un campo a otro, las semillas se transportan por el aire...)

- Conocimientos cotidianos sobre la falibilidad humana, enseñan a la población que las reglamentaciones oficiales siendo incluso bien intencionadas no siempre se aplican estrictamente.

- Conocimientos tanto sobre el comportamiento de las instituciones responsables del desarrollo y de la gestión de las innovaciones tecnológicas, como sobre los riesgos en affaires anteriores.

- Conocimientos de las prácticas capitalistas, según las cuales las grandes empresas persiguen el lucro, aun a pesar de los riesgos potenciales que puedan conllevar sus actividades y el saber que dichas empresas tienen poder suficiente para presionar en el mercado e instituciones en pro de sus intereses, etcétera.

Las representaciones sociales construidas por los españoles en torno a los alimentos transgénicos son, en general, ambivalentes. Aunque en primera instancia prevalezca una idea negativa, los informantes también expresan acuerdo y aceptan mejor estos alimentos si sus atributos resuelven problemas específicos -la intolerancia a la lactosa y al gluten, la reducción del uso de insecticidas- y siempre y cuando «no sea peor el remedio que la enfermedad». Los españoles no niegan las potencialidades de la ciencia ni que éstas puedan traducirse positivamente en productos o procesos beneficiosos para la salud o el medio ambiente. Sin embargo, desconfían de las políticas que dirigen dichas aplicaciones porque creen que están orientadas principalmente desde la obtención del lucro de las industrias agroalimentarias. De este modo, no es de extrañar que cuando las preguntas formuladas en los sondeos se orientan precisando tales expectativas, los resultados mejoren y la población parezca más dispuesta a aceptar ciertas aplicaciones biotecnológicas agrícolas, tal como muestran el último barómetro realizado en el 2002.

La segunda cuestión se refiere a las incertidumbres suscitadas por las biotecnologías alimentarias, que no se reducen únicamente a las consecuencias materiales de tales tecnologias. Los organismos genéticamente modificados son rechazados no sólo porque puedan ser poco útiles y potencialmente peligrosos para la salud o el medio ambiente, sino también porque son concebidos como el primer paso para la estandarización humana y animal. El uso experimental de la genética que se ha hecho en épocas históricas con grupos étnicos o religiosos, por ejemplo, aparece referido con frecuencia. Entonces, ¿por qué calificar de irracionales o erróneos dichos temores? Por su parte, las referencias éticas tienen un papel notable. A menudo se invoca a la naturaleza. La naturaleza es "otro" ser, posee valores, integridad, un poder propio que exige el respeto y la deferencia. La 
naturaleza es percibida como infinita en su complejidad y, al fin y al cabo, todavía desconocida para el ser humano. Es así como se hace una "llamada a la ética" de contenido algo indefinido; en cualquier caso, yendo contra el engaño empresarial y político y contra la manipulación del mundo vivo para según que fines:

- "¿Quiénes somos nosotros para alterar los mecanismos de la naturaleza?. La naturaleza tiene sus propias leyes y no debemos alterarlas sin saber qué consecuencias se pueden derivar..."

- "Llegará un momento en que nada será como tenía que ser. Ni los animales, ni las plantas, ni siquiera nosotros. Nosotros lo habremos cambiado todo a nuestro antojo, o mejor dicho, al antojo de unos pocos. ¿A quienes se les ocurre?. A la gente normal no. Son unos pocos los que están detrás. Siempre son los mismos, los que mandan, los que dirigen el mundo. Los que se benefician económicamente de todos estos experimentos...El dinero siempre está detrás ¿no?"

Este tipo de reflexiones sobre el alcance de las aplicaciones biotecnológicas son muy similares entre la población europea, aunque han dado paso, sin embargo, a diferentes actitudes culturales. En otros países como Dinamarca, Suiza o Francia se ha producido una demanda de debates públicos, de tal forma que los ciudadanos, ante la falta de respuestas definitivas y consistentes por parte de especialistas y políticos, han exigido el reconocimiento de su derecho a estar más cerca de los expertos en la producción de saber y de las técnicas aplicadas, de forma a permitirles dar respuestas a sus dudas, abriendo la investigación, escuchando las ideas de los ciudadanos, intercambiando argumentos, etc. También requieren estar más cerca de los políticos para que éstos recojan sus opiniones y legislen en consecuencia. Se trata, desde el punto de vista de la ciudadanía, de intercambiar dossiers que incluyan la pluralidad de intereses y posiciones y, en cierta manera, "democratizar" la ciencia.
Sin embargo, en España la producción y comercialización de los OGM no ha supuesto, exceptuando las manifestaciones de los sectores más críticos, una movilización importante de la población, ni se han creado el tipo de instituciones de iniciativa ciudadana con el fin de canalizar el debate. Respecto a esta situación de nuestro país, peculiar en lo que atañe al conjunto europeo. España es el estado de la Unión Europea con la mayor cantidad de superficie cultivada de plantas transgénicas (dos variedades de maíz en más de 20000 ha.) y el primer importador de maíz GM. No obstante, esta mayor implantación territorial no se ha correspondido, como cabría esperar, con una mayor reacción social, aunque en los últimos años haya aumentado la percepción negativa.

Se han planteado diferentes hipótesis al respecto. Algunas defienden que la opinión de la población española habría variado de la demás, a raíz controversia pública surgida en torno al periodo 1999-2000, momento en que los medios de comunicación empiezan a dar mayor cobertura a este tema. Esto coincidiendo con la intensificación del debate legislativo en el seno de la Unión Europea. La outra hipótesis, ampliamente aceptada entre políticos y expertos, mantiene que la percepción social del riesgo está performada por la mala información o excesiva información de que dispone el público, procedente en su mayor parte de los medios de comunicación, los cuales difunden sistemáticamente noticias sin contrastar y de origen dudoso. En este sentido, los consumidores se presentan como una especie de conglomerado investido por la marea mediática y moldeables, a favor o en contra de los organismos modificados genéticamente, al compás marcado por la presión informativa. Unos medios que, siguiendo la teoría de la agenda setting, condicionan a su vez la acción política y acaban situando en el orden del día, en las agendas, los temas a tratar y a resolver por los poderes públicos.

No cabe duda de que los medios de comunicación constituyen una de las principales fuentes de información y que la televisión, seguida 
de la radio y la prensa, son los medios preferidos por los españoles para obtener información sobre temas relacionados con la seguridad o inseguridad alimentaria ${ }^{58}$. De hecho, los telediarios e informativos son los programas que más ven y oyen nuestros informantes. Esta preferencia, sin embargo, depende de que los entrevistados sean lectores o no de prensa diaria y revistas científicas divulgativas, porque cuando se produce esta situación, los medios impresos se consideran fuentes más fiables y más didácticas que la televisión o la radio. Se lee, sin embargo, poca prensa diaria (el $26 \%$ de españoles la lee cada día frente al 39\% que no lo hace casi nunca). Tanto es así que numerosas personas reconocen que cuando consideran que un tema es importante, aún no siendo habitualmente lectores, adquieren la prensa para obtener «más y mejor» información.

Otra cuestión diferente es que el público haga una valoración positiva de la información mediática en periodos de crisis alimentarias. Cerca de la mitad de los informantes entrevistados dice que los medios suelen tratar estos temas enfatizando los aspectos negativos o polémicos frente a los positivos, recurriendo con excesiva facilidad a titulares sensacionalistas para ganar audiencia. En relación con la prensa, esta valoración se hace extensiva a los diarios no comprados habitualmente y que los lectores sitúan cerca o en oposición a las posiciones gubernamentales. Por otro lado, los informantes reconocen haber oído hablar por primera vez de alimentos transgénicos en la televisión o la prensa y solo un porcentaje muy bajo dice haber consultado expresamente otras fuentes de información especializadas para obtener más información. Si los medios, aún siendo «leídos» críticamente son una fuente de información básica, nos preguntamos de qué manera han podido influir en las representaciones sociales sobre los AMG. De forma sintética, los resultados de nuestro estudio apuntan en las siguientes direcciones ${ }^{(12)}$ :

- Los medios de comunicación social actúan de agentes activos en la controversia pública que acompaña a las situaciones de crisis alimentarias pudiendo contribuir, aunque solo parcialmente, en la configuración de las representaciones sociales sobre seguridad alimentaria. En el caso de los OGM, controversia pública no ha sido sinónimo de debate social.

- Los argumentos a favor o en contra de los OGM aparecen más en las manifestaciones de ciertos agentes implicados (políticos, científicos y asociaciones ecologistas o de consumidores) y en los argumentos mediáticos que en los discursos de la población.

- El tratamiento de la prensa y revistas españolas sobre los OGM no ha sido homogéneo, y el contenido expresa cuestiones muy variables abarcando información sobre las actuaciones y medidas políticas relativas a los OGM, acciones y pronunciamientos de los agentes sociales, estudios y resultados sobre las aplicaciones, noticias sobre la producción, distribución y comercialización de los productos transgénicos, entre los temas más relevantes.

\footnotetext{
12 El trabajo coordinado por el GEA de la Universidad de Barcelona ha realizado un vaciado mediático exhaustivo entre los años 1996 y 2001 procedente de diversos soportes representativos de la prensa diaria de ámbito estatal, revistas de divulgación científica, publicaciones de las asociaciones ecologistas y de entidades agrarias, revistas de consumidores y de carácter naturista y ecológico. En general, el contenido y la forma de tratar los OGM han sido diferentes entre la prensa diaria, las revistas científicas, los boletines y publicaciones de asociaciones ecologistas, sindicatos agrarios o las revistas de consumidores. Entre los soportes de los distintos medios también se han registrado ciertas diferencias en cuanto a la valoración de los OGM. Así por ejemplo, dentro de la prensa diaria las posiciones más diferenciadas las mantienen El Mundo y El País, el primero en una posición más favorable al discurso ecologista y el segundo recurriendo al criterio de los expertos en biotecnología con más frecuencia. Entre los soportes de los sindicatos agrarios también se observan divergencias entre las publicaciones del sindicato ASAJA y las revistas Vida Rural y Agricultura (al lado de la ciencia, el progreso económico) y las publicaciones de los sindicatos UPA o GOAG (temor al alcance de la ingeniería genética, alteración del orden natural, intereses ajenos al agricultor). Por su parte, las revistas ecologistas y de las asociaciones de consumidores coinciden en distintos puntos, aunque las diferencias son de fondo y de forma (maneras de actuar frente a/en contra la producción de OGM en el caso de los primeros y medidas a aplicar para su comercialización, especialmente relativas al etiquetaje, en el caso de las segundas).
} 
El tratamiento de los medios españoles sobre los OGM ha sido, desde una perspectiva diacrónica, bastante cíclico y la cobertura de noticias ha dependido sobre todo de los acontecimientos internacionales y especialmente de las directrices legislativas europeas. No obstante, coinciden en el tiempo con las ideas que la población se ha ido haciendo sobre este tema existiendo puntos de anclaje relativos a la ambivalencia que impregna una parte de las representaciones sociales. Ello no significa, sin embargo, que éstas hayan influido finalmente en su comportamiento real, como se ha señalado antes. Al margen de evidenciar con mayor o menor énfasis los discursos de los respectivos agentes, los medios apenas han dado cuenta de las actitudes $u$ opiniones de la población acerca de los AGM, limitándose a informar de las múltiples medidas legislativas y políticas adoptadas o de las acciones y pronunciamientos a favor o en contra de los principales grupos de presión implicados cuando han considerado que esas noticias eran de interés público. Ello evidencia, a su vez, que la intensidad y la amplitud de las crisis alimentarias no sólo dependen de que se haya difundido excesiva o deficiente información sobre los riesgos potenciales asociados a un tema concreto o que éste haya sido convertido en objeto de controversia pública por parte de expertos o políticos, sino también de las imágenes construidas por la población sobre el mismo fenómeno y si éstas han afectado o no a sus comportamientos cotidianos.

También es verdad que cuando los media cubren una historia específica, la gente la asume como importante, generándose una especie de cadena. De incertidumbres hay por doquier, pero algunas se convierten en socialmente preocupantes y otras no. Los líderes políticos tienden a responder con más probabilidad una vez que la incertidumbre se refleja en los media, ya que éstos prestan credibilidad y legitimidad a una parte de la controversia. Proveyendo un foro para la expresión, ciertos grupos pueden influir en las políticas públicas y las percepciones sociales a través de los soportes mediáticos y para ellos es crucial alcanzarlos. Ahora bien, las audiencias no son pasivas, ni los medios impresos escriben para lectores amorfos. Conocen su audiencia y saben que existen procesos individuales y sociales de la interpretación de las noticias en función de los propios roles individuales y de los grupos sociales a los que se pertenece. Así pues, las formas de construir la información, así como de leerla son múltiples. También las respuestas pueden serlo. La cobertura mediática puede estimular la movilización social y viceversa, pero esta relación no siempre es sistemática.

Según nuestra opinión, la explicación de las actitudes de la población española ha de explicarse mediante procesos que van más allá de la acción mediática. Por una parte, tienen que ver con el tipo de ambivalencia mostrada ante los AGM. Si por un lado, la mayor parte de los informantes ha expresado una opinión negativa sobre la aplicación de estas tecnologías en los alimentos, por otro lado dichas imágenes no se han materializado en actitudes de rechazo sistemático o de preocupación explícita a la hora de evitar los AGM en sus compras. Tratar de comprender el porqué de esta dualidad es importante para dar cuenta de las diversas actitudes: en el caso español coexiste una construcción social de los AGM que enfatiza los aspectos negativos (inutilidad, incertidumbre, escepticismo, peligro...) paralela a una aceptación pragmática de los productos que están en los lineales de los establecimientos alimentarios. La atención prestada al etiquetado de los alimentos se centra en el valor calórico de los alimentos, el tipo de grasas utilizadas o sobre si contiene o no ciertos aditivos. Solo un porcentaje muy pequeño de informantes (15\%) afirma evitar los alimentos que incluyen el calificativo de «modificado». Dicho de otro modo, como sucede en otros aspectos relativos al comportamiento alimentario, se evidencia un decalage entre lo que la gente dice o piensa acerca de los alimentos transgénicos y lo que finalmente consume, es decir, entre las representaciones sociales y las prácticas alimentarias. 
Por otra parte, tales actitudes diferentes tienen que ver con el hecho de que en España la controversia pública no se haya traducido en un «problema» de trascendencia social. Así, mientras que en nuestro país productores, políticos, biotecnólogos o activistas han protagonizado una controversia pública en base a intereses muy particulares, paralelamente no se ha registrado un debate social amplio exigiendo, como ha sucedido en Austria o Francia, una mejor información o una mayor participación en las decisiones científicas, políticas y legislativas a adoptar. Por tanto, no todas las reacciones frente a temas potencialmente conflictivos son del mismo orden. En torno a la EEB o mal de las vacas locas, la población española sí que tuvo una respuesta social inmediata, traduciéndose en el descenso brusco del consumo de carne de ternera, que llegó abajo de la mitad usual. Sin embargo, en el caso de los alimentos transgénicos no se ha exigido de forma masiva que cesaran los cultivos de plantas transgénicas, que no se los introdujeran en la cadena alimentaria o que los productos que contienen tales sustancias fueran retirados del mercado. La explicación de estas diferencias se encuentra en la valoración distinta que la población ha dado a ambos temas, en consecuencia tanto de la percepción de la proximidad y del alcance del riesgo (consecuencias) y de las razones para aceptarlo o rechazarlo, como de la gestión política y del tratamiento mediático que se les ha dado. En la esfera política o mediática, los consumidores y sus potenciales intereses han ocupado un lugar más que secundario.

Así pues, concluimos que la incerteza que la población asocia a los AGM tiene, en cualquier caso, un origen empírico, fundadas en buena medida sobre el comportamiento precedente de las instituciones responsables por el desarrollo y la reglamentación de las innovaciones tecnológicas y por el control de los riesgos de la cadena alimentaria. Así, mientras numerosos políticos y expertos han considerado pequeños los riesgos ligados a los alimentos transgénicos y argumentado que la población no fundamenta sus respuestas en base a conocimientos científicos, las imágenes sociales que se han ido generando señalan en otras direcciones: de momento hacia un cuestionamiento relativo de la utilidad de dichos alimentos, una desconfianza sobre la neutralidad política de las evaluaciones de los posibles riesgos y un escepticismo ante la aplicación de los aspectos potencialmente más positivos. El contenido de estos tres ejes señala diferencias significativas entre las representaciones que, sobre las reacciones del público, han construido quienes gestionan, regulan y deciden estos temas, formuladas habitualmente en términos de falta de conocimientos suficientes o de inquietudes nocientíficas y las representaciones construidas por el conjunto mismo de la población, formuladas a partir de lógicas profanas y otras experiencias previas, incluso previsibles. Nos indican, además, que estos especialistas, así como los propios medios de comunicación, tienen dificultades para captar o reflejar la esencia de las incertidumbres colectivas y para reconocer los factores socioculturales que las determinan. En consecuencia, no es de extrañar que, cuando cuando estalla una alarma alimentaria, los mecanismos institucionales utilizados para gestionar y resolver la crisis sean poco eficaces y acaben teniendo como resultado efectos contrarios a los deseables, es decir, resulten en el incremento de las incertidumbres y en el aumento de la desconfianza entre la población. Si en un futuro se produjera algún fenómeno que cuestionase decididamente la inocuidad de los alimentos transgénicos y el riesgo se percibiera como una amenaza tangible, se reafirmarían los atributos negativos de las representaciones sociales ya existentes y ello podría afectar de forma directa a las prácticas alimentarias y a la evitación de su consumo, aunque fuera sólo temporalmente

\section{REFERENCIAS}

1. Food and Agriculture Organization. El estado de inseguridad en el mundo 2003 [Acceso: 2003 oct 23]. Disponible: http://www.fao.org 
2. Fischler C. La maladie de la vache folle. In: Apfelbaum M, diretor: Risques et peurs alimentaires. París: Odil Jacob; 1998.

3. Apfelbaum M, diretor. Risques et peurs alimentaires. París: Odil Jacob; 1998.

4. Hubert A. Pas de panique! (alimentaire). París: Marabout; 2002.

5. Bredahl L. Consumers' Cognitions with regard to genetically modified foods. Results of a qualitative study in four countries. Appetite 1999; 33: 343-60.

6. Chateauraynaud F, Torny D. Surveiller et contenir: un monde peuplé de prions", Les sombres precurseurs. Une sociologie pragmatique de I'alerte et du risque. París: Éditions de I'EHESS; 1999.

7. Latouche K, Rainelli P, Vermesch D. Food safety issues and the BSE scare: some lessons from the French case. Food Policy 1999; 23(5):347-56.

8. Peretti-Watel P. Sociologie du risque. París: Armand Colin; 2000

9. Crédoc. Manger est perçu comme présentant davantge de risques. Consommation et modes de vie 2001 abr; 148.

10. Centro de investigaciones sociológicas. Opiniones y actitudes de los españoles hacia la biotecnología. Estudio 2412. Madrid; 2001.

11. Beck U. La sociedad del riesgo, Hacia una nueva modernidad. Barcelona: Paidós; 1996.

12. Beck U. La sociedad del riesgo global. Madrid: Siglo XXI; 2002.

13. Giddens A. Les consequences de la modernité. París: L'Harmattan; 1994.

14. Giddens A, Risk. Lecture 2 [Acceso 2001 jul 1]. Disponible: http://www.news.bbc. co.uk/hi/english/ static/events/reith_99/email.htm

15. Bauman Z. La postmodernidad y sus descontentos. Madrid: Akal; 2001

16. Bauman Z. Freedom. Open University Press; 1998.

17. Douglas M, Wildavsky A. Risk and culture. University of California Press; 1983.
18. Douglas M. Risk and blame: Essays in Cultural Theory. London: Routledge; 1992.

19. Douglas M. La aceptabilidad del riesgo según las ciencias sociales. Barcelona: Paidos; 1996.

20. Bellaby P. To risk or no to risk? Uses and limitation of Mary Douglas on risk-acceptability for understanding health and safety at work and road accidents. J Am Acad Arts Sci 1990; 119(4): 465-83.

21. Boltanski L, Thévenot L. De la justification: les économies de la grandeur. Paris: Gallimard; 1991.

22. Beardsworth A, Keil T. Sociology on the menu. An invitation to the study of food and society. London: Routledge; 1997.

23. Lupton D. Food, risk and subjectivity. In: Williams SJ, editor. Health, Medicine and Society, Key Theories, Futur Agendas. London: Routledge; 2000.

24. Theys J. Postface. VVAA: Conquête de la sécurité, gestion des risques. Paris: L’Harmattan; 1991.

25. Slovic P. The perception of risk. London: Earthscan; 2000.

26. Peretti-Watel P. La société du risque. París: La Decouverte; 2001.

27. Hoban J. The construction of food Biotechnology as a social issue. In: Maurer D, Sobal J, editors. Eating agendas. Food and nutrition as social problems. New York: Aldine de Gruyter; 1995.

28. Duclos. Puissance et faiblesse du concept de risque. L'Année Sociologique 1996; 46(2):309-37.

29. Ewald F. Philosophie de la précaution. L'Année Sociologique 1996; 46(2):383-412.

30. Fischler $C$. Raison et déraison dans les perceptions des risques alimentaires. Cahiers de Nutr et de Diététique 1998; 33(5):297-301.

31. Jodelet D. Représentations sociales: un domaine en expansion. VVAA Les représentations sociales. París: PUF; 1989.

32. Abric JC. Les représentations sociales: aspects théoriques. VVAA. Practiques socials et representations. Paris: PUF; 1994. 
33. Lahlou S. Penser manger. Alimentation et représentations sociales. París: PUF; 1998.

34. Riechmann J. Cultivos y alimentos transgénicos. Una guía crítica. Madrid: Los libros de la Catarata; 2000 .

35. Ramón D, Calvo D. Debate en torno a la comercialización de los alimentos transgénicos", Arbor. Ciencia, Pensamiento y Cultura 2001; CLXVIII, 661:171-86.

36. Food and Agriculture Organization. 20 preguntas sobre los alimentos genéticamente modificados (GM) [Acceso 2003 oct 23]. Disponible: http:// www.fao.org

37. Simon A. Toting up the aearly haverst of transgenic plants. Science 1998, 282:2177

38. Gura T. New genes boost rice nutrients. Science 1999; 285:994-5.

39. Dossier: Société du Risque. Fantasmes et realité, realizado conjuntamente con la Cité Des Sciencies et de I'Industrie Xlles Entretiens de la Villette, París. Sciences Humanes 2002: 124, febrero.

40. Roy A. Les experts face au risque: le cas des plantes transgéniques. París: Presses Universitaires de France; 2001.

41. Cuerda JC, et al. Relaciones Ciencia/Tecnología en torno a la biotecnología vegetal: el caso de Andalucía. Sevilla: Instituto de Desarrollo Regional, Fundación Universitaria; 2000.

42. Gaskell G, Bauer M, editors. Biotechnology 1996 to 2000. The Years of Controversy. London: Science Museum; 2001.

43. Caceres J, et al. Percepción de la biotecnología agroalimentaria en Europa. Ciencia, Medicina, Comunicación y Cultura 2001; 21: julio-diciembre.

44. Cheveigné S, Boy D, Gallaux JC. Les biotechnologies en débat. Pour une démocartie scientifique. París. Balland; 2002.

45. Eurobarometros. European, science and technology. 1996, 1999. Disponible: URL: http:// www.infogm.fr
46. Eurobarometer 55.2. European, science and technology. Bruselas: Unión Europea/EORG; 2001.

47. Centro de Investigaciones Sociologicas (CIS). Opiniones y actitudes de los españoles hacia la biotecnología. Estudio 2414. Madrid; 2001.

48. Centro de Investigaciones Sociologicas (CIS). Opiniones y actitudes de los españoles hacia la biotecnología. Estudio 2412. Madrid; 2001.

49. Centro de Investigaciones Sociologicas (CIS). La ciencia avanza. Estudio 2242. Madrid; 1997.

50. Centro de Investigaciones Sociologicas (CIS). Ciencia y tecnología. Estudio 2213. Madrid; 1996.

51. Frewer LJ, Shepherd R. Ethical concerns and risk perceptions associated with the perceived need for regulation of the technology. Agric Hum Values 1995; 12: 48-57.

52. Gaskell, Allum N, Stares S, coordenador. Europeans and Biotechnology in 2002. 2nd ed. Eurobarometer 58.0; 2003 Mar.

53. Pabe. Perceptions publiques des biotechnologies agricoles en Europe resumé [Acceso 2002 oct 7]. http://www.inra.fr/sed/science-gouvernance

54. Gracia M. La alimentación en el umbral del siglo XXI: una agenda para la investigación sociocultural en España. In: Gracia M, coordenador. Somos lo que comemos. Barcelona: Ariel; 2002.

55. Krueger A. El grupo de discusión. Guía práctica para la investigación aplicada. Madrid: Pirámide; 1991.

56. Morgan DL. The focus group guidebook. Londres: Sage; 1995.

57. Kitzinger J, Barbour RS. Introduction: the challenge and promise of focus group. In: Barbour RS, Kitzinger J, editors. Developing focus group research: politics, theory and practice. Londres: Sage; 1999.

58. Centro de investigaciones sociologicas (CIS). Los españoles y los medios de comunicación. Madrid: Estudio 2396; 2000.

Recebido para publicación en 9 de febrero de 2004. 